\title{
The heterogeneous and regressive consequences of COVID-19: Evidence from high quality panel data ${ }^{\text {th }}$
}

\author{
Thomas F. Crossley ${ }^{\mathrm{a}}$, Paul Fisher ${ }^{\mathrm{b}}$, Hamish Low ${ }^{\mathrm{c}, *}$ \\ ${ }^{a}$ European University Institute, IFS, ESCoE and Understanding Society, Italy \\ ${ }^{\mathrm{b}}$ ISER, University of Essex and Understanding Society, United Kingdom \\ ${ }^{\mathrm{C}}$ University of Oxford, IFS and Understanding Society, United Kingdom
}

\section{A R T I C L E I N F O}

\section{Article history:}

Received 10 August 2020

Revised 8 November 2020

Accepted 10 November 2020

Available online 14 November 2020

\section{JEL codes:}

$\mathrm{C} 83$

D31

J63

Keywords:

COVID-19

Job loss

Inequality

Mitigation

Financial distress

\begin{abstract}
A B S T R A C T
Using new data from the first two waves of the Understanding Society COVID-19 Study collected in April and in May 2020 in the UK, we study the labour market shocks that individuals experienced in the first wave of the pandemic, and the steps they and their households took to cope with those shocks. Understanding Society is based on probability samples and the Covid-19 Study is constructed carefully to support valid population inferences. The Covid-19 Study collected novel data on the mitigation strategies that individuals and households employ. Further, prior observation of respondents in the panel allows us to characterize regressivity with respect to pre-pandemic economic positions. Our key findings are that those with precarious employment, aged under 30 and from minority ethnic groups faced the biggest labour market shocks. Almost $50 \%$ of individuals have experienced declines in household earnings of at least $10 \%$, but declines are most severe in the bottom pre-pandemic income quintiles. Methods of mitigation vary substantially across groups: borrowing and transfers from family and friends are most prevalent among those most in need.
\end{abstract}

(c) 2020 The Authors. Published by Elsevier B.V. This is an open access article under the CC BY license (http:// creativecommons.org/licenses/by/4.0/).

\section{Introduction}

The onset of COVID-19 has caused a substantial contraction in economic activity, partly through individuals changing their behaviour in the face of the health risks and partly because of restrictions introduced by governments. In this paper we show that the scale of the economic impact of the COVID shock in the UK is very different for different people. These differences arise partly because the direct impact differs depending on individual characteristics and what sort of work people do, and partly because individuals take different steps to mitigate the shock. Further,

\footnotetext{
We are grateful to Alexandra Brown for research assistance. The Understanding Society COVID-19 Study is funded by the Economic and Social Research Council (ES/ K005146/1) and the Health Foundation (2076161). Fieldwork for the survey is carried out by Ipsos MORI and Kantar. Understanding Society is an initiative funded by the Economic and Social Research Council and various Government Departments, with scientific leadership by the Institute for Social and Economic Research, University of Essex. The research data are distributed by the UK Data Service. Further details and initial analysis of the Understanding Society COVID-19 Study circulated as Benzeval et al. (2020b). All errors are our own.

* Corresponding author.

E-mail addresses: thomas.crossley@EUI.eu (T.F. Crossley), pfishe@essex.ac.uk (P. Fisher), hamish.low@economics.ox.ac.uk (H. Low).
}

government schemes to mitigate the impact may benefit some but not others. The paper highlights the idiosyncratic nature of the economic shocks and shows how heterogeneity across households and differences in methods of mitigating shocks mean the same economic shock has very different implications.

Our work makes three contributions to understanding the economic effects of COVID-19 and the role of the UK government in mitigating those effects. First, our results are based on a large, high quality longitudinal survey derived from probability samples. We use the first two waves of the Understanding Society COVID-19 Study alongside information from the long-running Understanding Society Main Study. We show the importance of using carefully modelled inverse probability weights and data derived from proper probability samples to capture accurately the differential effects of the aggregate shock; we also provide statistical tests of the efficacy of the weighting strategy. Second, the long panel of pre-COVID-19 data provides a clear picture of pre-pandemic economic positions, and this provides crucial context with which to assess the regressivity of the economic consequences of the pandemic. Third, to address who is best able to mitigate the crisis and how the government has mitigated the crisis, the COVID-19 web surveys provide novel information on what mechanisms have mitigated losses for 
individuals. These three contributions enable us to provide a unique perspective on how COVID-19 has changed the economic reality faced by different individuals in the UK.

The backdrop to these changes in labour market status is how the UK government supported workers and households. The UK went into "lockdown" on 23rd March and the economy contracted substantially in March and April. The economy then began to grow again but by the end of May, GDP was still 24\% below its level in February. ${ }^{1}$ In terms of economic support policies, the UK government introduced the Coronavirus Job Retention Scheme on March 20th, soon followed by the Self-Employment Support Scheme. The UK government pursued a policy of explicitly protecting jobs through the Job Retention Scheme whereby workers were "furloughed" by their firms. This meant $80 \%$ of pay would be covered by a government subsidy, subject to a maximum of $£ 2500$, and was conditional on the worker not providing any hours of work. As a result, rates of unemployment remained low at around 4\% through the first wave of the pandemic. This strategy is in contrast to the US where support operated through additional payments to the unemployed, and the unemployment rate rose quickly to $14.7 \%$.

We split our analysis into showing differences in the economic shock to labour markets and then into showing differences in actions take to mitigate the economic shock. We find substantial impacts on labour markets, but these impacts do not show up in employment levels which changed very little between February and the end of May. On the other hand, the fraction who are working a positive number of hours declined by 25 percentage points by the end of April, followed by a slight bounce back. The difference between the fraction employed and the fraction working positive hours highlights the effect of the Job Retention Scheme at keeping workers in the same jobs.

There is however substantial heterogeneity in the economic impact and mitigation strategies across groups. The young and those without any guaranteed hours of work experienced substantial falls in hours worked at the onset of COVID, and corresponding large falls in household earnings. But by the end of May, the decline in hours worked for these groups had been partly reversed, and further, household earnings showed less cumulative declines at this stage than for other groups. Mitigation of earnings losses by the young and precariously employed was partly through savings, but key components were finding new work and moving onto universal credit. Again, these mitigation strategies were very different from other groups.

Black, Asian and minority ethnic (BAME) groups experienced different labour market shocks from non-BAME groups. ${ }^{2}$ The decline in the fraction working positive hours was similar between BAME and non-BAME groups, but the reason that hours fell differed markedly. Whereas the decline for non-BAME groups was primarily driven by being moved onto the Job Retention Scheme rather than into unemployment, the decline among BAME groups was driven in equal measure by being moved into unemployment. Comparing the groups, among those whose hours fell, 15 percentage points fewer from BAME groups were put on the Job Retention Scheme, and 13 percentage points more made unemployed. Further, the earnings losses that resulted were mitigated in different ways: the incidence of borrowing was higher among BAME groups, as was the incidence of transfers from family and friends.

Finally, we use the data from the main Understanding Society study to show how regressive the crisis has proved to be: those in the lowest pre-pandemic average income quintiles have had the worst experiences. They have experienced the largest declines in the fraction working positive hours, and the largest declines in household earn-

\footnotetext{
1 https://www.ons.gov.uk/economy/grossdomesticproductgdp/bulletins/gdpmonthlyestimateuk/august2020.

2 Sample size limitations mean we cannot disaggregate further.
}

ings. For those in these lowest quintiles, these losses were mitigated by borrowing and by transfers from family and friends.

This pattern of regressive impacts of COVID-19 arrives after three decades of worsening inequality in gross earnings in the UK (Blundell et al., 2018). This long run trend towards greater inequality has been primarily due to declines in working hours lower down the distribution. The regressive impact of COVID-19 on work patterns exacerbates this: the percentage declines in working hours are greater for the bottom two quintiles. The long-run increase in inequality has been offset by expansions in the government safety net in the UK over the past 30 years that mean net household income inequality actually fell. However, cuts in benefit generosity in the years immediately prior to COVID-19 meant that there was already less protection for low income households (Bourquin et al., 2020). Further, the evidence we show through the first wave of COVID is that much of the mitigation of the decline in earnings has come through using private saving or transfers.

Our results contribute to a fast-moving literature looking at the labour market consequences of COVID-19 and the impact of government support schemes. Much of the evidence comes from rapid surveys with quota samples, or convenience samples ex post calibrated to population totals on the basis of a limited number of observable characteristics like age and gender. For example, Adams-Prassl et al. (2020) report large effects in the U.K. on the young, on women and on those in insecure work, and (Belot et al., 2020) report a similar age effect. These studies have given initial indications of the effects of COVID-19 for the sample surveyed, but can only provide population estimates under very strong assumptions about sample inclusion and response.

For the US, the March 2020 US Current Population Survey is derived from reliable probability samples and it shows increased unemployment, decreased working hours, but little fall in wages (Béland et al., 2020). Cortes and Matias (2020) shows that the labour market impacts were bigger for men, younger workers, Hispanics, and the less educated, although (Montenovo et al., 2020) finds larger effects for women and those with larger families. Couch et al. (2020) find employment rates for Latinx were disproportionately hit, whereas African-Americans were not. On the other hand, the lack of a furlough scheme in the US means that, unlike the UK, there is no distinction to draw between being furloughed and being unemployed. Larger shocks for vulnerable populations have also been documented in data from probability samples for the Netherlands (von Gaudecker et al., 2020) and Germany (Schröder et al., 2020); and from population registers for Norway (Alstadsæter et al., 2020). The present paper is the first to report credible population estimates for the UK.

The paper proceeds as follows: Section 2 gives addition detail about our data and Section 3 discusses drawing population inferences from survey data. Section 4 documents changes in employment and hours from a pre-pandemic baseline in February 2020 through April and May of 2020. Section 5 reports the impact of these shocks on household earnings, and Section 6 documents the heterogeneity in the steps taken to mitigate the impact of households earnings losses. Section 7 concludes.

\section{Data}

This paper is based on the first two waves of the Understanding Society COVID-19 study (henceforth COVID-19 Study), fielded in, respectively, late April and late May of 2020; these surveys also collected retrospective information about February 2020. ${ }^{3}$ The

\footnotetext{
${ }^{3}$ Further information on the Understanding Society COVID-19 Study can be found in Institute for Social and Economic Research (2020b) and Institute for Social and Economic Research (2020a).
} 
COVID-19 study is built upon Understanding Society: the UK Household Longitudinal Study (henceforth the Main Study) and uses monthly web surveys to capture the experiences and behaviour of Main Study participants during the COVID-19 pandemic. This means, first, that the COVID-19 Study inherits the properties of the Main Study that ensure reliable population inferences, and second, that data collected by the COVID-19 Study can be linked to data collected on the same participants, and their households, by past waves of the Main Study. ${ }^{4}$

With minor exceptions, all members of the Main Study who were aged sixteen or over in April 2020, and who belonged to active households, were invited to participate in the COVID-19 Study. ${ }^{5}$ Pre-notification letters introducing the study were sent to 42,330 Main Study members on 17 April. Of these, 32,596 had completed the Wave 9 annual interview in 2017/18 (the latest released wave of the Main Study). Respondents were offered a small financial incentive for each web survey. Subsequently, invitations to each web survey were sent by email and/or SMS text message, or by post. Each web survey had a 7-day fieldwork period and reminders were sent on days 2,3 , and 6 . $^{6}$ Each web questionnaire took approximately 20 min to complete.

Among those who had given a full adult interview in the Wave 9 annual interview, the response rates to April and May web surveys were $48.6 \%$ and $49.1 \%$ respectively. ${ }^{7}$ These response rates are similar to the response rates of large government surveys in the UK. ${ }^{8}$ These are also very good response rates for a voluntary web survey that attempts to contact a known set of individuals (so that nonrespondents are identified: convenience and quota samples do not have knowable response rates). Nevertheless, this is significantly below the 85-90\% overall wave-on-wave retention rate that the Main Study achieves by following up web non-respondents by direct interviewer contact.

There were 17,452 respondents to the April web survey and 14,811 in May. Most of our analysis focuses on individuals that reached the end of both surveys. ${ }^{9}$ The COVID-19 study weighting strategy, which we describe in more detail in the next section, and which is the basis for our population inferences, assigns a positive sample weight to respondents who also responded to Wave 9 of the Main Study and had a positive Wave 9 sample weight. This gives a basic analysis sample of 10,892 individual respondents. We further restrict our attention on respondents aged 20 to 65 in order to focus on the working age population and exclude a small number of respondents who provide incomplete information in February 2020 on hours of work or employment. This gives a final analysis sample of 7,404 individuals.

The fact that the Covid-19 study is based on a pre-existing panel study means that we can document not only how shocks vary across individuals but how those shocks vary by pre-pandemic

\footnotetext{
${ }^{4}$ Understanding Society (University of Essex Institute for Social and Economic Research, NatCen Social Research, and Kantar Public, n.d.) is the UK's main longitudinal Household Survey, and one of the largest household panel studies in the world. It began in 2009 but carries on from the earlier British Household Panel survey which ran from 1991 to 2008.Understanding Society attempts to interview all adults in sample households annually and has a mixed mode design, with some panel members responding via a face-to-face interview and some completing a web interview.

${ }^{5}$ An active household is one that participated in at least one of the last two waves of the main study.

6 The first web survey was fielded on April 24th and the second on May 27th.

7 5,519 fewer main sample members were invited to the May survey, as some April non-respondents were issued to a telephone follow up survey instead, and a further group either entirely opted out of the COVID-19 study at the April invitation or were determined to be no longer eligible.

${ }^{8}$ For example, the Labour Force Survey - to which many web surveys with quota or convenience samples calibrate - has response rate of about $55 \%$ at the first wave, falling with subsequent and about $40 \%$ overall. The Family Resources Survey which is the basis for official income statistics had a response rate of 52\% in 2017/18.

9 That is, individuals who were "full respondents" in both April and May.
}

economic position. For our distributional analysis we created a measure of "average pre-COVID-19" income. This measure averages household net income across up to three previous waves of the main study, and assigns individual respondents to quintiles of income on that basis. ${ }^{10}$ For this purpose income includes earned and unearned income, net of tax and inclusive of any benefits received, equivalised by household composition. It is important to note that the COVID-19 study is individual-based, and supports inferences about the distribution of income (for example) across adults rather than across households. Household income and other household variables are viewed as attributes of individuals.

\section{Population inferences}

Distributional analysis is inherently about estimating finite population quantities and gradients. The ability of the Main Study, and by extension the COVID-19 Study, to deliver credible population estimates rests on the fact that the Main Study is based on probability samples, and on the use of carefully designed inverse-probability (IP) weights. ${ }^{11}$

A defining feature of probability samples is that every unit in the target population has a knowable, nonzero probability of selection (Valliant and Dever, 2018). This offers two important advantages over other types of samples (such as convenience or quota samples). First, the fact that all units in the target population have a nonzero probability of selection ensures that, with sufficiently large sample sizes, the full range of heterogeneity in the target population will be captured. Second, known selection probabilities mean that consistent estimates of population parameters and associated inferences can be obtained with well-established statistical methods involving IP weighting (see Wooldridge (2002) and the references therein).

Of course, real samples deviate from the theoretical ideal of a probability sample because of non-response, including, in the case of longitudinal studies, attrition. Nevertheless, there are multiple advantages to beginning from probability samples. First, while statistical adjustments may be needed to account for nonrandom attrition and non-response, such adjustments will be smaller if the initial selection probabilities are known. Second, when a study begins with a probability sample, useful information is often available on non-respondents. This is particularly true in longitudinal studies where rich information on individuals who attrit is available from past waves of the survey. When information is available on both respondents and non-respondents, the models of response probability that underlay IP weights can be estimated directly. In contrast, with convenience or quota samples information is only available for respondents, and the relationship between response probabilities and observable characteristics can only be inferred indirectly by comparing sample characteristics to external totals. ${ }^{12}$ This approach leads to what we refer to as "calibration weights" because the procedure calibrates a sample with entirely unknown inclusion probabilities to external totals. This procedure is less efficient, but more importantly, the set of variables used in the adjustment is typically very limited (for example, just age, education and gender). As discussed in Moffit et al. (1999), Wooldridge (2002), weights correct for selection on observables, and so the richness of observable predictors of response is critical. Finally, other types of samples may have a zero probability that certain parts of the target

\footnotetext{
1095 percent of the sample uses the full 3 observation average, 4 percent uses 2 observations and the remaining cases use one observation only.

11 The Understanding Society Main Study is a combination of four different probability samples. See University of Essex Institute for Social and Economic Research, NatCen Social Research, and Kantar Public (n.d.) for more details.

12 Ideally those totals would come from a census or register, but in practice they
} often come from a probability-sample based survey. 
population will enter the sample. No weighting scheme can overcome the complete absence of a subgroup from the sample.

The Main Study employs state of the art methods to minimize non-response and attrition. It also provides carefully-modelled IP weights to account for the nonrandom nature of the remaining attrition. ${ }^{13}$ The extent to which the Main Study is "representative", in the sense of supporting high quality inferences about population quantities, is continually evaluated: see Benzeval et al. (2020a) and the references therein. ${ }^{14}$ The study has been judged repeatedly to be of high quality: as just one example, Main Study income data aligns well with national statistics on the income distribution in the UK (Fisher et al., 2019). Given this robust evidence that (suitably weighted) waves of the Main Study provide reliable estimates of population quantities and gradients, the remaining issue is nonresponse to COVID-19 Study among respondents to Wave 9 of the Main Study.

IP weights are released with each wave of the COVID-19 Study. ${ }^{15}$ These weights were created via an adjustment to the cross-sectional weights available for Wave 9 of the Main Study. This means that the probability of response to each wave in the COVID-19 Study is modeled as the product of the conditional probability of response to that survey (given Main Study Wave 9 response) and the probability of Wave 9 response. The conditional probability of a response to a COVID-19 wave is modeled as a function of information known at the time of issue to the COVID-19 Study. The resulting weights map the set of respondents to a given COVID-19 wave back to the target population at the time of Wave $9(2017 / 18) .{ }^{16}$

The choice set of predictors for response include basic demographics, household composition, economic variables and health variables, all drawn from the rich information collected by past waves of the Main Study. Note again that because the target sample is drawn from the Main Study, this information is available for both respondents and non-respondents to the COVID-19 Study. In addition, both the econometrics and survey statistics literatures (Moffit et al., 1999; Nicoletti and Peracchi, 2005) emphasize the importance of including in weighting models variables that predict response and are potentially correlated with outcomes being studied, but are unlikely to be including in standard economic or social science models. Examples include previous survey outcomes, survey design variables and survey paradata. Several such variables turn out to be good predictors of the conditional probability of response in the COVID-19 Study. These include indicator variables for the types of contact information the survey team held about the respondent prior to the COVID-19 Study (email address, mobile phone number, both, neither) and the realized mode of previous waves of the main survey. The former may affect the salience of the survey request while the latter may be related to how easily the respondent would find it to complete a web survey. Either could quite plausibly be related to whether the respondent is employed or to the kind work they do. Variable selection for the final models from the initial set is done by LASSO.

In addition to the cross-sectional weights for the April and May waves, we also employ a weight for the balanced panel of individuals who responded to both the April and May waves. This weight was derived using the same methods.

It is common place to assess survey weights or weighted data by comparing summary statistics to some benchmark. We go further and offer a formal statistical test for whether the weights capture the probability of retention to wave $t$ of a longitudinal data set,

\footnotetext{
13 The development of the Main Study weights is described in Lynn and Olena (2010).

14 "Representative" is a widely-used but ill-defined term. See the discussion in Benzeval et al. (2020a).

15 The weights were developed by the authors of this paper.

${ }^{16}$ Updated for subsequent mortality and emigration, but not immigration.
}

given response at wave $t-1$, and then apply this test to the COVID-19 Study (given response to Wave 9 of the Main study.) While the literature contains a number of tests for whether panel attrition is random (see for example, Fitzgerald et al., 1998), the test we propose tests instead whether the weights deal adequately with nonrandom attrition. ${ }^{17}$

Let $Y_{t-1, i}$ be an observation of any variable of interest, $Y$ for individual $i$ in wave $t-1 ; R_{t, i}=1$ if $i$ responds to wave $t$ (of the COVID19 Study) and 0 otherwise; and similarly $R_{t-1, i}=1$ if the individual responds to wave $t-1$ (here Wave 9 of the Main Study). $X_{t-1, i}$ is a set of predictors of response observed for both respondents and nonrespondents, prior to the realization of $R_{t, i}$ (up to and including time $t-1) . X_{t-2, i}$ is defined analogously. Note that these may contain lagged values of $Y$. Let $w_{t-1, i}\left(X_{t-2, i}\right)<\infty$ be the wave $t-1$ weight. This is the inverse of the wave $t-1$ response probability. Analogously, $w_{t, i}\left(X_{t-1, i}\right)<\infty$ is the wave $t$ weight. In this case, this is one of the COVID-19 Study IP weights. $s_{t-1, i}=\frac{w_{t-1, i}}{\sum w_{t-1, i}}$ is the wave $t-1$ weight share and $s_{t i}$ is is the wave $t$ weight share, defined in the same way.

Under the joint null that

$E\left[R_{t-1, i} \mid Y_{t-1, i}, X_{t-2, i}\right]=E\left[R_{t-1, i} \mid X_{t-2, i}\right]=1 / w_{t-1, i}\left(X_{t-2, i}\right)$

and

$E\left[R_{t, i} \mid X_{t-1, i}, Y_{t-1, i}\right]=E\left[R_{t, i} \mid X_{t-1, i}\right]=1 / w_{t, i}\left(X_{t-1, i}\right)$,

i.e. the response to the relevant waves is independent of $Y_{t-1}$ given pre-response observables: ${ }^{18}$

$E\left[s_{t-1, i} R_{t-1, i} Y_{t-1, i}-s_{t, i} R_{t, i} Y_{t-1, i}\right]=0$

This moment condition captures the fact that under the joint null, either combination of respondents and associated weights provide a consistent estimate of $E\left[Y_{t-1, i}\right]$, and this provides a simple statistical test of the adequacy of the weights. All of the sets of weights developed for the Covid-19 Study are subjected to these tests, for a wide range variables of interest $\left(Y_{t-1, i}\right)$. As an illustration, Table 1 reports the results of test of this type using the Wave 1 (April) crosssection weight. The first column shows the estimated population mean of $Y_{t-1, i}$ using the Wave 9 (main study) response sample and associated Wave 9 weights. The next three columns show estimates of the same mean using only respondents to the April COVID19 Study, either unweighted (Column 2), with a crude calibration weight (Column 3), or with the full IP weights (Column 4). The calibration weight matches the April COVID-19 Study data to the Wave 9 Main Study data on the basis of set of cells defined by gender, age and education. It mimics the kind of calibration weights often employed with convenience samples, or the composition of a quota sample. ${ }^{19}$ Previous research (Couper et al., 2007; Schonlau et al., 2009) has concluded that weighting on demographics alone is unlikely to deal adequately with selection into web surveys. Nevertheless, patterns of internet use have changed significantly over the past fifteen years, so we take the opportunity to revisit the issue here.

The last two columns report test statistics based on Eq. (1) and associated p-values, for the calibration weights (column 5) and full IP weights (Column 6). The test is reported for an illustrative set of variables, $Y_{t-1, i}$, with each row of the table corresponding to a different $Y_{t-1, i}$. These $Y_{t-1, i}$ variables are presented in two groups. The first group are variables that are included in the estimated model of response to Wave 1 of the COVID-19 Study. These include measures of subjective financial satisfaction, housing tenure, occupa-

\footnotetext{
17 Similar tests are reported in Schonlau et al. (2009).

18 We also require the technical condition $E\left[Y_{t-1, i} w_{t-1, i}\right]<\infty$ and $E\left[Y_{t-1, i} w_{t, i}\right]<\infty$; Wooldridge (2002).

${ }^{19}$ See for example Adams-Prassl et al. (2020) and Belot et al. (2020).
} 
Table 1

Statistical testing of survey weights.

\begin{tabular}{|c|c|c|c|c|c|c|}
\hline & \multirow{2}{*}{$\begin{array}{c}\text { Wave } 9 \\
\text { Weighted }\end{array}$} & \multicolumn{3}{|c|}{ Covid } & \multicolumn{2}{|c|}{ Test } \\
\hline & & Unweighted & $\begin{array}{c}\text { Calibration } \\
\text { weight }\end{array}$ & $\begin{array}{l}\text { Full IP } \\
\text { weight }\end{array}$ & Calibration & Full IP \\
\hline \multicolumn{7}{|l|}{ In Full IP weight only: } \\
\hline $\begin{array}{l}\text { Living comfortably/ } \\
\text { doing alright }\end{array}$ & 0.71 & 0.76 & 0.76 & 0.71 & $\begin{array}{c}-0.04 * * * \\
(0.000)\end{array}$ & $\begin{array}{c}0.00 \\
(0.632)\end{array}$ \\
\hline Just about getting by & 0.21 & 0.18 & 0.18 & 0.21 & $\begin{array}{l}0.03 * * * \\
(0.000)\end{array}$ & $\begin{array}{c}0.00 \\
(0.616)\end{array}$ \\
\hline $\begin{array}{l}\text { Finding it quite/ } \\
\text { very difficult } \\
\text { Housing tenure: }\end{array}$ & 0.07 & 0.06 & 0.06 & 0.08 & $\begin{array}{l}0.01 * * * \\
(0.000)\end{array}$ & $\begin{array}{c}-0.01 \\
(0.109)\end{array}$ \\
\hline Owned & 0.34 & 0.40 & 0.41 & 0.33 & $\begin{array}{c}-0.06 * * * \\
(0.000)\end{array}$ & $\begin{array}{c}0.01 \\
(0.076)\end{array}$ \\
\hline Mortgage & 0.34 & 0.42 & 0.40 & 0.36 & $\begin{array}{c}-0.07 * * * \\
(0.000)\end{array}$ & $\begin{array}{c}-0.02 * * * \\
(0.000)\end{array}$ \\
\hline Rented & 0.13 & 0.09 & 0.09 & 0.12 & $\begin{array}{l}0.03 * * * \\
(0.000)\end{array}$ & $\begin{array}{c}0.00 \\
(0.487)\end{array}$ \\
\hline Social Housing & 0.19 & 0.09 & 0.10 & 0.19 & $\begin{array}{l}0.09 * * * \\
(0.000)\end{array}$ & $\begin{array}{c}0.00 \\
(0.587)\end{array}$ \\
\hline Low skill occupation & 0.38 & 0.29 & 0.33 & 0.38 & $\begin{array}{l}0.05 * * * \\
(0.000)\end{array}$ & $\begin{array}{c}-0.00 \\
(0.802)\end{array}$ \\
\hline Any savings income & 0.36 & 0.45 & 0.44 & 0.37 & $\begin{array}{c}-0.08 * * * \\
(0.000)\end{array}$ & $\begin{array}{c}-0.01 \\
(0.086)\end{array}$ \\
\hline $\begin{array}{l}\text { Behind with some or } \\
\text { all bills }\end{array}$ & 0.05 & 0.03 & 0.03 & 0.05 & $\begin{array}{l}0.02 * * * \\
(0.000)\end{array}$ & $\begin{array}{c}0.00 \\
(0.685)\end{array}$ \\
\hline \multicolumn{7}{|c|}{ In neither weighting model: } \\
\hline Poverty & 0.15 & 0.11 & 0.12 & 0.14 & $\begin{array}{l}0.03 * * * \\
(0.000)\end{array}$ & $\begin{array}{c}0.01 \\
(0.320)\end{array}$ \\
\hline Receives core benefit & 0.05 & 0.03 & 0.03 & 0.05 & $\begin{array}{l}0.02 * * * \\
(0.000)\end{array}$ & $\begin{array}{c}-0.00 \\
(0.755)\end{array}$ \\
\hline Behind with housing & 0.09 & 0.06 & 0.06 & 0.09 & $\begin{array}{l}0.03 * * * \\
(0.000)\end{array}$ & $\begin{array}{c}0.00 \\
(0.730)\end{array}$ \\
\hline Smoker & 0.15 & 0.09 & 0.10 & 0.13 & $\begin{array}{l}0.05 * * * \\
(0.000)\end{array}$ & $\begin{array}{c}0.02 * * \\
(0.002)\end{array}$ \\
\hline Long-standing illness & 0.38 & 0.34 & 0.34 & 0.36 & $\begin{array}{l}0.04 * * * \\
(0.000)\end{array}$ & $\begin{array}{c}0.02 * \\
(0.029)\end{array}$ \\
\hline
\end{tabular}

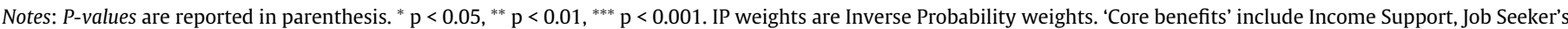
Allowance and Universal Credit.

tion, savings behavior and financial arrears. Table 1 demonstrates that the null is rejected for calibration weights for all of these variables, but when the full IP weights are employed, the null is rejected only for the percentage owning a home with a mortgage. The magnitude of the moment is the difference between the weighted sample mean of the variable $Y_{t-1, i}$ and its target value in the Wave 9 Main Study. A comparison of the two columns shows that the reduction in the size of this difference is economically significant when moving from the calibration weights to the full IP weights. For example, using the calibration weights, we would overestimate the fraction of individuals reporting that they were living comfortably by 4 percentage points, and overestimate the fraction managing to save some of their income by 8 percentage points, and underestimate the fraction of individuals living in social housing by 9 percentage points.

The second set of $Y_{t-1, i}$ variables we consider are those that are not included in the the estimated model of response. These are indicators for being in poverty, in receipt of core benefits, in arrears on rent or mortgage payments, being a current smoker, or having a long-standing illness. These Wave 9 target variables that are not in the response model potentially give a better indication of the ability of the Covid-19 IP weights to support population inferences about variables measured in the Covid-19 study (as such variables are observed only for respondents and so cannot be included in response models.).

Again we see that the null is always rejected with the calibration weights, but less often when the full IP weights are employed.
The calibration weights lead to an overestimate of all of the conditions, by between 2 and 5 percentage points. The point to stress is that IP weights reduce the bias in all cases, and eliminate it entirely in some. The results in Table 1 indicate that IP weights associated with the COVID-19 Study are very effective in adjusting for nonrandom attrition between Wave 9 of Main study and the COVID19 Study, and that the IP weights provide much a more credible basis for population inferences than simple calibration weights.

Finally, the underlying Understanding Society samples are clustered and stratified random samples, and so the COVID-19 sample inherits this structure. We appropriately adjust standard errors for the resulting design effects.

\section{Labour market shocks}

In this section, we show the extent of heterogeneity and regressivity in the labour market shocks that individuals face, and how these shocks have evolved in the first three months of the pandemic. We describe labour market status using two main measures: whether an individual is employed and whether they are working a positive number of hours. We chose these measures because the UK Coronavirus Job Retention Scheme aims to maintain the employment relationship despite individuals not working any hours.

In Table 2, we show the fraction employed (columns 1-4) and the fraction working positive hours (columns 5-7) using reports 
Table 2

Labour market shocks by individual characteristics.

\begin{tabular}{|c|c|c|c|c|c|c|c|c|}
\hline & Empl. X-sec. (Feb) & Empl. (Feb) & Empl. (April) & Empl. (May) & +ve hours (Feb) & +ve hours (April) & +ve hours (May) & Group size (\%) \\
\hline $\begin{array}{l}\text { All } \\
\text { Gender: }\end{array}$ & 79 & 79 & 77 & 77 & 79 & 54 & 58 & 100 \\
\hline Men & 83 & 83 & 80 & 81 & 82 & 57 & 61 & 46.8 \\
\hline Women & 76 & 76 & 74 & 74 & 75 & 51 & 55 & 53.2 \\
\hline \multicolumn{9}{|l|}{ Ethnicity: } \\
\hline Not BAME & 80 & 80 & 78 & 79 & 80 & 54 & 59 & 89.8 \\
\hline BAME & 71 & 70 & 63 & 64 & 69 & 48 & 50 & 10.2 \\
\hline \multicolumn{9}{|l|}{ Age: } \\
\hline Age $20-29$ & 78 & 76 & 69 & 72 & 75 & 44 & 52 & 19.8 \\
\hline Age 30-39 & 86 & 86 & 84 & 84 & 85 & 58 & 62 & 19.5 \\
\hline Age $40-49$ & 85 & 86 & 85 & 85 & 85 & 63 & 6 & 22.2 \\
\hline Age $50-59$ & 80 & 81 & 80 & 80 & 81 & 57 & 61 & 26.5 \\
\hline Age 60-65 & 59 & 57 & 55 & 55 & 57 & 37 & 40 & 12.1 \\
\hline \multicolumn{9}{|l|}{ Household type: } \\
\hline Adult, no child & 69 & 72 & 69 & 70 & 72 & 50 & 55 & 12.6 \\
\hline Adult, child & 71 & 72 & 72 & 72 & 71 & 46 & 48 & 3.2 \\
\hline Adults, no child & 78 & 77 & 74 & 74 & 76 & 52 & 56 & 47.2 \\
\hline Adults, child & 85 & 85 & 83 & 84 & 84 & 57 & 63 & 37.0 \\
\hline \multicolumn{9}{|l|}{$\begin{array}{l}\text { Pre-COVID-19 income } \\
\text { quintile: }\end{array}$} \\
\hline 1 & 60 & 62 & 58 & 59 & 61 & 37 & 39 & 18.9 \\
\hline 2 & 78 & 76 & 73 & 73 & 76 & 45 & 51 & 20.2 \\
\hline 3 & 85 & 85 & 83 & 84 & 85 & 57 & 63 & 20.6 \\
\hline 4 & 87 & 86 & 84 & 85 & 85 & 62 & 66 & 20.5 \\
\hline 5 & 86 & 86 & 84 & 83 & 84 & 67 & 69 & 19.8 \\
\hline \multicolumn{9}{|l|}{ Worker type: } \\
\hline Fixed hours & 100 & 100 & 96 & 97 & 99 & 71 & 76 & 67.7 \\
\hline Flexible hours & 100 & 100 & 95 & 95 & 98 & 73 & 74 & 7.2 \\
\hline Emp. sets (sure min.) & 100 & 100 & 96 & 96 & 98 & 62 & 65 & 8.2 \\
\hline Emp. sets (no min.) & 100 & 100 & 69 & 78 & 95 & 34 & 44 & 3.1 \\
\hline Self-employed & 100 & 100 & 96 & 95 & 99 & 54 & 64 & 13.8 \\
\hline
\end{tabular}

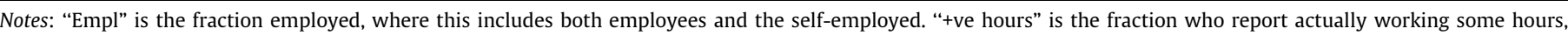

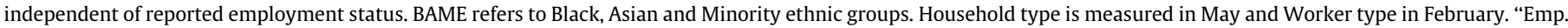

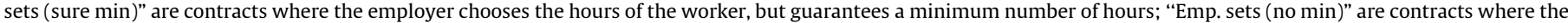

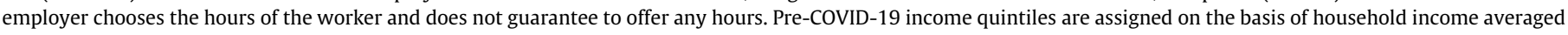

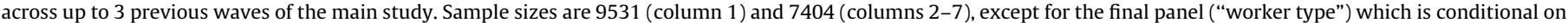
employment in February.

on February, April and May 2020. The table disaggregates these measures by individual characteristics, including gender, ethnicity, age, average pre-COVID-19 income quintile, household type and worker type. The first column shows (retrospective) numbers for the February 2020 employment "baseline" using the April respondent sample and associated cross-sectional weights. The remaining columns of the Table are based on the balanced panel of respondents to both April and May surveys, and the associated balanced panel weight. Comparing the first and second column confirms that the balanced panel (and associated weight) matches very closely the full cross-sectional numbers at a point in time. ${ }^{20}$ Column 8 reports the weighted group size to show the size of the groups affected. Table 6 in the Online Appendix reports the unweighted group sizes and actual numbers of observations by group.

The table shows that, in aggregate, employment levels have changed very little between February and late May. This highlights clearly the effectiveness of the government Coronavirus Job Retention Scheme that aimed to preserve employment. On the other hand, the fraction of individuals who are working a positive number of hours fell 25 percentage points to April and only $54 \%$ of working age individuals were working positive hours. There was a slight recovery to $58 \%$ in the fraction working positive hours in May. However, the key point is that the difference between the fraction employed and the fraction working-positive-hours high-

\footnotetext{
${ }^{20}$ We present the February employment comparison as an illustration but this is also true of other measures and at other points in time.
}

lights starkly the potential unemployment problem when the Job Retention Scheme finally ends. ${ }^{21}$

The absence of any impact on employment is difficult to reconcile with the substantial job losses reported by Adams-Prassl et al. (2020). However, our numbers are consistent with the only other probability-sample based employment data for the UK that we are aware of, the Office of National Statistic's Labour Force Survey. That data also show almost no change in employment up to May $2020 .^{22}$

The breakdown by individual characteristics in Table 2 shows that while the labour market consequences have been felt across the board, there are some groups that have been particularly impacted, and others that were initially impacted but have rebounded more. Hardest hit initially were those individuals where the employer does not guarantee any minimum number of hours: of those employed on such a zero hours contract in February, the fraction working positive hours fell by the end of April from $95 \%$ to $34 \%$. This was followed by a 10 percentage point bounce back in May. Sharp initial declines in the fraction working positive hours and in employment were seen for those aged under 30 , but again has bounced back a little. This highlights the double-

\footnotetext{
${ }^{21}$ We have focused our discussion on the discrete measure of whether or not individuals are working positive hours. Additionally, we have the actual hours worked. The patterns observed for this continuous measure are very similar to those for the discrete indicator.

22 https://www.ons.gov.uk/employmentandlabourmarket/peopleinwork/employ-
} mentandemployeetypes/bulletins/uklabourmarket/june2020. 
Table 3

Reasons for decline in hours by May.

\begin{tabular}{|c|c|c|c|c|c|c|c|}
\hline & $\%$ with hours fall & Emp. cuts & Furlough & Unemp. & Loss of self-emp. business & Health & Caring \\
\hline $\begin{array}{l}\text { Report an hours fall } \\
\text { Gender: }\end{array}$ & 63 & 10 & 36 & 8 & 10 & 6 & 7 \\
\hline Men & 63 & 10 & 35 & 9 & 12 & 6 & 5 \\
\hline Women & 63 & 10 & 36 & 8 & 9 & 6 & 8 \\
\hline \multicolumn{8}{|l|}{ Ethnicity: } \\
\hline Not BAME & 63 & 10 & 37 & 7 & 10 & 6 & 6 \\
\hline BAME & 64 & 12 & 22 & 20 & 13 & 10 & 13 \\
\hline \multicolumn{8}{|l|}{ Age: } \\
\hline Age 20-29 & 66 & 9 & 46 & 18 & 5 & 5 & 3 \\
\hline Age 30-39 & 61 & 9 & 36 & 7 & 8 & 4 & 15 \\
\hline Age $40-49$ & 60 & 8 & 33 & 4 & 12 & 6 & 11 \\
\hline Age 50-59 & 63 & 13 & 32 & 6 & 12 & 7 & 2 \\
\hline Age 60-65 & 67 & 8 & 29 & 10 & 14 & 11 & 1 \\
\hline \multicolumn{8}{|l|}{ Household type: } \\
\hline Adult, no child & 59 & 15 & 28 & 14 & 9 & 8 & 1 \\
\hline Adult, child & 60 & 13 & 46 & 2 & 10 & 2 & 13 \\
\hline Adults, no child & 62 & 10 & 38 & 9 & 9 & 6 & 2 \\
\hline Adults, child & 64 & 9 & 35 & 7 & 11 & 6 & 14 \\
\hline \multicolumn{8}{|l|}{$\begin{array}{l}\text { Pre-COVID-19 income } \\
\text { quintile: }\end{array}$} \\
\hline 1 & 69 & 13 & 35 & 12 & 14 & 9 & 8 \\
\hline 2 & 69 & 10 & 44 & 8 & 9 & 6 & 8 \\
\hline 3 & 62 & 9 & 44 & 5 & 8 & 5 & 6 \\
\hline 4 & 59 & 9 & 32 & 9 & 7 & 5 & 6 \\
\hline 5 & 58 & 9 & 22 & 9 & 13 & 6 & 7 \\
\hline \multicolumn{8}{|l|}{ Worker type: } \\
\hline Fixed hours & 56 & 11 & 43 & 8 & 0 & 5 & 5 \\
\hline Flexible hours & 67 & 8 & 29 & 8 & 0 & 2 & 11 \\
\hline Emp. sets (sure min.) & 72 & 19 & 49 & 6 & 0 & 6 & 4 \\
\hline Emp. sets (no min.) & 89 & 11 & 49 & 35 & 0 & 4 & 3 \\
\hline Self-employed & 86 & 2 & 6 & 6 & 53 & 11 & 14 \\
\hline
\end{tabular}

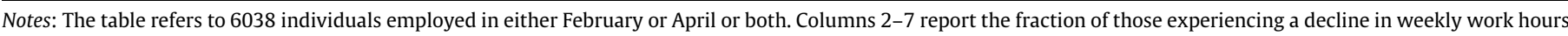

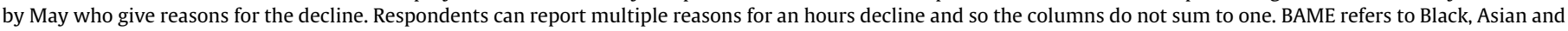

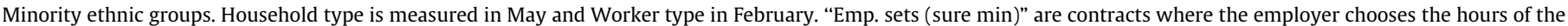

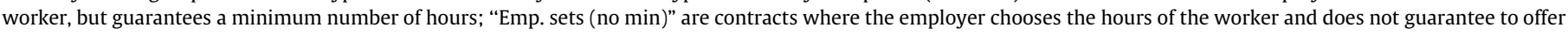
any hours. Pre-COVID-19 income quintiles are assigned on the basis of household income averaged across up to 3 previous waves of the main study.

edged nature of the flexibility that comes with zero-hours contracts and the sort of jobs typically carried out by young workers. Looking at the labour market impact by ethnicity, individuals from minority ethnic groups experienced a substantially larger fall in employment than others, whereas the overall decline in the fraction working positive hours was similar. Across the distribution, the bottom three quintiles experienced the greatest reductions in the fraction working positive hours. Tables 7 and 8 in the Online Appendix reports regression results for labour market status and the change in labour market status, respectively, using the same covariates as Table 2 . The regression results confirm the differential effects shown in Table 2, and in particular the larger impacts on BAME groups and the lower income quintiles.

Table 3 shows reported reasons for the fall in hours worked for those who have experienced a decline by the end of May. In the population, $63 \%$ of individuals reported some decline in hours worked. This decline in hours may be caused directly by the health shock, indirectly by impacts on the economy due to the health shock, or for non-health related reasons. The first point to take from Table 3 is that the decline in hours is driven by the economic restrictions rather than directly by health or caring. Over $36 \%$ of those reporting a decline in hours were part of the Coronavirus Job Retention Scheme and so had substantial earnings replacement. In addition, $8 \%$ report the decline in their hours being caused by being made unemployed. By contrast, only $6 \%$ report health as a reason for the decline in hours, and 7\% report caring for others. However, these averages mask considerable heterogeneity across different types of individual. Caring is more important for those with children; and the effect of health restricting work increases sharply with age.

Ethnicity is associated with a very different explanation for the hours decline: individuals from minority ethnic (BAME) groups are 15 percentage points less likely to be supported by the Job Retention Scheme. Instead, they are 13 percentage points more likely to cite unemployment as the reason for their hours decline. This greater prevalence of unemployment among minority ethnic groups was also shown in Table 2 above.

Our overall conclusion is that the labour market effects are highly heterogeneous, particularly impacting the young, zero hours workers and minority ethnic groups; and are regressive, penalizing most the lower quintiles of the average pre-COVID-19 income distribution. The final point that Table 3 highlights is the importance of the Coronavirus Job Retention Scheme in the UK which has maintained many of those not actually working any hours notionally in employment. This is in marked contrast with the US where support operated through the extension of unemployment insurance without the same direct attempt to maintain attachment to the employer.

\section{Earnings losses}

Section 4 showed that the effect of the COVID crisis on labour market outcomes varies substantially across individuals and across the distribution. The Coronavirus Job Retention Scheme moderates the link between hours and earnings for individuals, and the evi- 
Table 4

Household earnings pre and post Covid.

\begin{tabular}{|c|c|c|c|c|c|c|c|c|c|}
\hline & \multirow{3}{*}{ Feb } & \multirow{3}{*}{$\begin{array}{l}\text { April } \\
\text { Mean }\end{array}$} & \multirow{3}{*}{ May } & \multicolumn{6}{|c|}{ \% change since Feb } \\
\hline & & & & \multicolumn{3}{|c|}{ April } & \multicolumn{3}{|c|}{ May } \\
\hline & & & & p25 & p50 & p75 & p25 & p50 & p75 \\
\hline $\begin{array}{l}\text { All } \\
\text { Gender: }\end{array}$ & 549 & 501 & 478 & -18 & 0 & 0 & -41 & -6 & 6 \\
\hline $\begin{array}{l}\text { Men } \\
\text { Women }\end{array}$ & $\begin{array}{l}573 \\
526\end{array}$ & $\begin{array}{l}519 \\
484\end{array}$ & $\begin{array}{l}490 \\
467\end{array}$ & $\begin{array}{l}-17 \\
-18\end{array}$ & $\begin{array}{l}0 \\
0\end{array}$ & $\begin{array}{l}0 \\
0\end{array}$ & $\begin{array}{l}-44 \\
-38\end{array}$ & $\begin{array}{l}-7 \\
-5\end{array}$ & $\begin{array}{l}5 \\
6\end{array}$ \\
\hline $\begin{array}{l}\text { Age: } \\
\text { Age 20-29 } \\
\text { Age 30-39 } \\
\text { Age } 40-49 \\
\text { Age 50-59 } \\
\text { Age } 60-65\end{array}$ & $\begin{array}{l}503 \\
564 \\
571 \\
593 \\
446\end{array}$ & $\begin{array}{l}454 \\
526 \\
534 \\
534 \\
386\end{array}$ & $\begin{array}{l}482 \\
502 \\
487 \\
508 \\
346\end{array}$ & $\begin{array}{l}-20 \\
-14 \\
-16 \\
-18 \\
-30\end{array}$ & $\begin{array}{l}0 \\
0 \\
0 \\
0 \\
0\end{array}$ & $\begin{array}{l}0 \\
0 \\
0 \\
0 \\
0\end{array}$ & $\begin{array}{l}-32 \\
-40 \\
-42 \\
-40 \\
-76\end{array}$ & $\begin{array}{l}-2 \\
-5 \\
-8 \\
-5 \\
-13\end{array}$ & $\begin{array}{c}20 \\
5 \\
1 \\
5 \\
9\end{array}$ \\
\hline $\begin{array}{l}\text { Ethnicity: } \\
\text { Not BAME } \\
\text { BAME }\end{array}$ & $\begin{array}{l}564 \\
411\end{array}$ & $\begin{array}{l}515 \\
370\end{array}$ & $\begin{array}{l}490 \\
368\end{array}$ & $\begin{array}{l}-17 \\
-22\end{array}$ & $\begin{array}{l}0 \\
0\end{array}$ & $\begin{array}{l}0 \\
0\end{array}$ & $\begin{array}{l}-40 \\
-42\end{array}$ & $\begin{array}{l}-6 \\
-4\end{array}$ & $\begin{array}{l}5 \\
8\end{array}$ \\
\hline $\begin{array}{l}\text { Household type: } \\
\text { Adult, no child } \\
\text { Adult, child } \\
\text { Adults, no child } \\
\text { Adults, child }\end{array}$ & $\begin{array}{l}560 \\
266 \\
588 \\
523\end{array}$ & $\begin{array}{l}471 \\
230 \\
540 \\
487\end{array}$ & $\begin{array}{l}461 \\
249 \\
518 \\
457\end{array}$ & $\begin{array}{l}-50 \\
-20 \\
-17 \\
-17\end{array}$ & $\begin{array}{l}0 \\
0 \\
0 \\
0\end{array}$ & $\begin{array}{l}0 \\
0 \\
0 \\
0\end{array}$ & $\begin{array}{l}-51 \\
-33 \\
-42 \\
-38\end{array}$ & $\begin{array}{c}-2 \\
0 \\
-5 \\
-8\end{array}$ & $\begin{array}{l}3 \\
2 \\
9 \\
4\end{array}$ \\
\hline $\begin{array}{l}\text { Pre-COVID-19 income } \\
\text { quintile: }\end{array}$ & & & & & & & & & \\
\hline $\begin{array}{l}1 \\
2 \\
3 \\
4 \\
5\end{array}$ & $\begin{array}{l}287 \\
395 \\
487 \\
664 \\
860\end{array}$ & $\begin{array}{l}245 \\
356 \\
444 \\
593 \\
817\end{array}$ & $\begin{array}{l}228 \\
365 \\
428 \\
559 \\
765\end{array}$ & $\begin{array}{l}-31 \\
-20 \\
-15 \\
-14 \\
-12\end{array}$ & $\begin{array}{l}0 \\
0 \\
0 \\
0 \\
0\end{array}$ & $\begin{array}{l}0 \\
0 \\
0 \\
0 \\
0\end{array}$ & $\begin{array}{l}-60 \\
-36 \\
-34 \\
-43 \\
-39\end{array}$ & $\begin{array}{l}-13 \\
-6 \\
-3 \\
-8 \\
-2\end{array}$ & $\begin{array}{l}4 \\
7 \\
4 \\
4 \\
8\end{array}$ \\
\hline Worker type: & & & & & & & & & \\
\hline Fixed hours & 624 & 598 & 556 & -10 & 0 & 0 & -30 & -2 & 5 \\
\hline Flexible hours & 704 & 660 & 616 & -9 & 0 & 0 & -36 & -2 & 6 \\
\hline Emp. sets (sure min.) & 479 & 455 & 433 & -21 & 0 & 0 & -42 & -14 & 6 \\
\hline Emp. sets (no min.) & 605 & 369 & 512 & -44 & -20 & 0 & -35 & 0 & 59 \\
\hline Self-employed & 551 & 390 & 466 & -64 & -25 & 0 & -57 & -24 & 6 \\
\hline
\end{tabular}

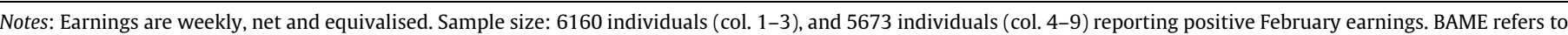

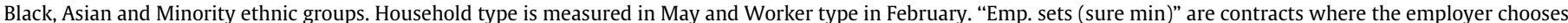

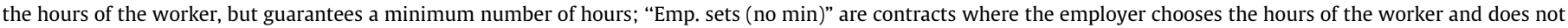
guarantee to offer any hours. Pre-COVID-19 income quintiles are assigned on the basis of household income averaged across up to 3 previous waves of the main study.

dence in Section 4 shows that for many groups, it has been effective in doing so. Individual earnings losses may be cushioned by the earnings of other household members. In this section, we consider how the labour market shocks documented above translate into changes in net household earnings for different households.

Table 4 reports the impact on household earnings through April and May, and across the distribution. The measure of earnings we use is net, equivalised weekly household earnings of the individual respondents, including earnings from employment and selfemployment. ${ }^{23}$ Average household earnings declined by $10 \%$ by the end of April, with a further 5\% decline by the end of May. The right-hand side of Table 4 shows the distribution of the change in earnings, showing the 25th percentile, the median and the 75th percentile, and separately for April and for May. This highlights the extent of losses and the extent that these losses have worsened: the 25th percentile of the change was an $18 \%$ decline by April, but by May the 25 th percentile was a $41 \%$ decline. The median earnings change has also deteriorated. On the other hand, the 75th percentile of the earnings change is positive in May.

\footnotetext{
${ }^{23}$ In the COVID-19 Study, individual and household earnings are collected with single questions. This differs from the main study, which aggregates information from more detailed questions, but was necessitated by the strategy of brief, but frequent, web surveys. (Micklewright and Schnepf, 2010) is one assessment of such "single question" income data collection in surveys. Individual earnings are top-coded at $£ 4000$ net per week, and household earnings is top-coded where the difference between household and individual earnings exceeds $£ 4000$ net per week.
}

When we consider the impact on earnings by average preCOVID-19 income level, the impact is increasingly severe the lower down the average pre-COVID-19 income distribution. In the bottom quintile, the median fall in earnings was $13 \%$ by May, whereas in the top quintile, the median fall was only $2 \%$. The differences are equally stark at the 25th percentile of the percentage change: in the bottom quintile, the 25 th percentile fall was $60 \%$. The impact of COVID on earnings has been highly regressive.

There is also substantial heterogeneity both between and within groups. Between groups, the young initially experienced greater earnings changes, but by May, this position had reversed. Indeed, by May, in terms of earnings declines, young individuals show the least negative impact of any age group on household earnings. This rebound in earnings reflects the labour market changes over time shown in Table 2. Among the young, there was also a range of winners and losers: at the 75th percentile, the change in earnings was a $20 \%$ increase. Similar within group heterogeneity is seen for those on zero-hour contracts and for the self-employed.

\section{Mitigation}

The declines in household earnings documented above do not necessarily translate into declines in household income or living standards. Benefits, particularly Universal Credit, moderate the link between earnings and income, and individuals and households may take additional steps to moderate the link between income 


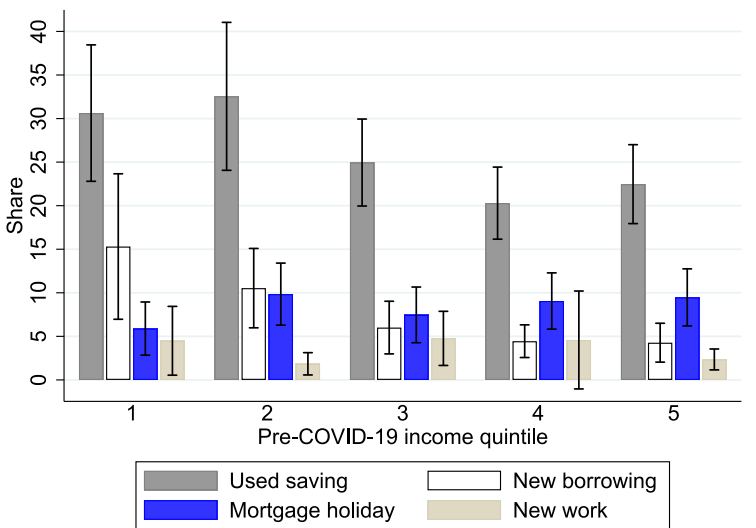

(a) Self-Insurance

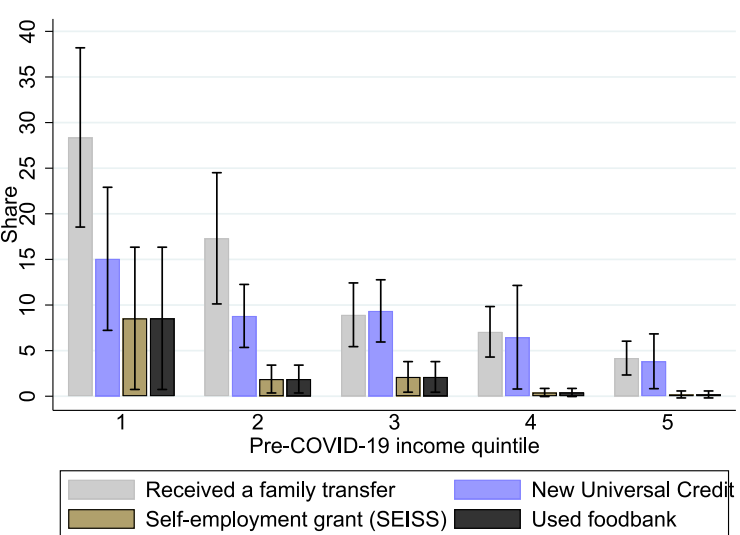

(b) External

Fig. 1. Sources of Mitigation.

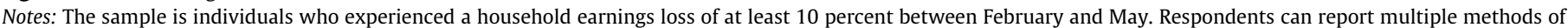

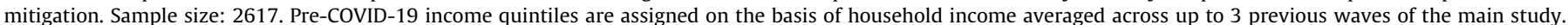

Table 5

Mitigating earnings losses.

\begin{tabular}{|c|c|c|c|c|c|c|c|c|c|}
\hline & $\begin{array}{c}\% \text { with earn. } \\
\text { loss }\end{array}$ & $\begin{array}{c}\text { Used } \\
\text { savings }\end{array}$ & Borrowed & $\begin{array}{l}\text { New } \\
\text { work }\end{array}$ & $\begin{array}{c}\text { Mortgage } \\
\text { hol. }\end{array}$ & $\begin{array}{c}\text { New Universal } \\
\text { credit }\end{array}$ & SEISS & $\begin{array}{c}\text { Family transfer } \\
\text { etc. }\end{array}$ & $\begin{array}{c}\text { Used } \\
\text { foodbank }\end{array}$ \\
\hline $\begin{array}{l}\text { All } \\
\text { Gender: }\end{array}$ & 45 & 26 & 8 & 3 & 8 & 8 & 8 & 12 & 2 \\
\hline Men & 47 & 25 & 8 & 4 & 7 & 9 & 10 & 12 & 1 \\
\hline Women & 44 & 27 & 8 & 3 & 10 & 7 & 7 & 13 & 4 \\
\hline \multicolumn{10}{|l|}{ Ethnicity: } \\
\hline Not BAME & 45 & 25 & 7 & 3 & 8 & 8 & 8 & 12 & 2 \\
\hline BAME & 42 & 36 & 21 & 4 & 11 & 11 & 12 & 15 & 3 \\
\hline \multicolumn{10}{|l|}{ Age: } \\
\hline Age 20-29 & 41 & 22 & 10 & 8 & 5 & 14 & 4 & 18 & 3 \\
\hline Age 30-39 & 45 & 23 & 9 & 4 & 13 & 9 & 6 & 16 & 2 \\
\hline Age $40-49$ & 46 & 25 & 11 & 3 & 13 & 8 & 11 & 11 & 1 \\
\hline Age 50-59 & 45 & 32 & 6 & 2 & 6 & 9 & 10 & 12 & 1 \\
\hline Age 60-65 & 51 & 26 & 2 & 1 & 2 & 3 & 8 & 4 & 7 \\
\hline \multicolumn{10}{|l|}{ Household type: } \\
\hline Adult, no child & 44 & 25 & 7 & 6 & 5 & 21 & 9 & 22 & 4 \\
\hline Adult, child & 37 & 35 & 22 & 5 & 5 & 5 & 5 & 40 & 12 \\
\hline Adults, no child & 43 & 26 & 4 & 2 & 4 & 7 & 7 & 8 & 3 \\
\hline Adults, child & 48 & 25 & 11 & 4 & 14 & 7 & 10 & 14 & 1 \\
\hline \multicolumn{10}{|l|}{$\begin{array}{l}\text { Pre-COVID-19 } \\
\text { income } \\
\text { quintile: }\end{array}$} \\
\hline 1 & 52 & 31 & 16 & 4 & 6 & 14 & 11 & 27 & 8 \\
\hline 2 & 46 & 32 & 11 & 2 & 10 & 9 & 11 & 17 & 2 \\
\hline 3 & 40 & 25 & 6 & 5 & 8 & 9 & 6 & 9 & 2 \\
\hline 4 & 47 & 21 & 4 & 4 & 9 & 6 & 4 & 7 & 0 \\
\hline 5 & 42 & 23 & 4 & 2 & 10 & 4 & 9 & 4 & 0 \\
\hline \multicolumn{10}{|l|}{ Worker type: } \\
\hline Fixed hours & 40 & 21 & 6 & 2 & 9 & 4 & 0 & 9 & 1 \\
\hline Flexible hours & 42 & 18 & 4 & 1 & 7 & 6 & 0 & 5 & 0 \\
\hline Emp. sets (sure min.) & 53 & 22 & 11 & 6 & 5 & 17 & 0 & 16 & 1 \\
\hline Emp. sets (no min.) & 41 & 25 & 3 & 31 & 16 & 36 & 0 & 11 & 1 \\
\hline Self-employed & 59 & 53 & 15 & 7 & 12 & 23 & 54 & 17 & 1 \\
\hline
\end{tabular}

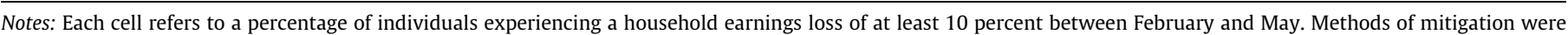

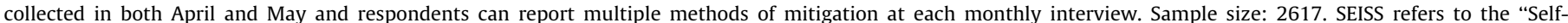

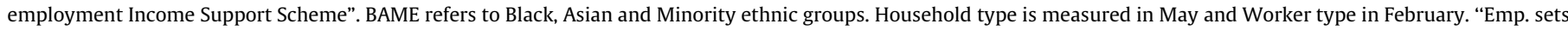

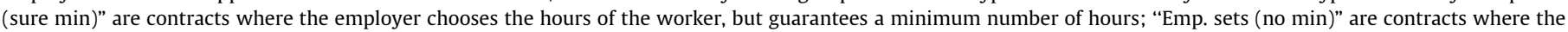

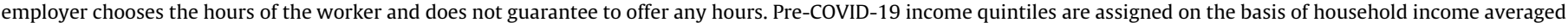
across up to 3 previous waves of the main study.

and living standards. The COVID-19 web surveys provide novel information on the different mechanisms used by individuals to mitigate losses. In this section, we document the incidence of different mitigation strategies, including applications for universal credit, dis-saving, borrowing, transfers from friends and family and the use of food banks. The point we stress is that in addition to the heterogeneity in impact on earnings, there are important differences in mitigation across groups and across individuals. 
Fig. 1 summarizes steps taken to mitigate earnings losses by individuals who have reported a decline in household earnings of $10 \%$ or more by May. Just under half of the population have experienced such a loss, but the extent of lost earnings would have been substantially larger without the protection of the Coronavirus Job Retention Scheme. We split the additional mitigation steps taken into "Self-insurance" and "External" steps. Mitigation through self-insurance includes the use of savings, borrowing, additional work, or mortgage holidays. Mitigation from external sources includes transfers from other family or friends as well as making new applications for state benefits (through universal credit) or the use of food banks.

At this stage in the crisis, more individuals had used selfinsurance, and in particular their own savings, than had accessed external help to mitigate losses: more than a quarter had drawn down their savings. Significant numbers had also increased borrowing or asked for a mortgage holiday. New applications for Universal Credit were $8 \%,{ }^{24}$ but overall less prevalent than savings or family transfers.

Table 5 provides a breakdown of mitigation for different groups. ${ }^{25}$ Different groups of individuals used very different mechanisms. Across the income distribution, borrowing and transfers from family and friends increased sharply as average pre-COVID-19 income declines. Borrowing and transfers were also much more marked for single parents; and similarly for minority ethnic groups, where increased borrowing was three times as likely. By contrast, for those on zero hour contracts, a third reported finding new work and a third reported newly receiving universal credit.

The key question these results raise is how long support from family and friends, or from individuals' own saving and borrowing, can continue. The end of the Job Retention Scheme will lead to more widespread and deeper earnings losses potentially at the same time as these support mechanisms will potentially be exhausted.

\section{Conclusions}

This paper shows that the aggregate effects of COVID-19 mask considerable differences in how individuals are affected both because they are differentially exposed to the labour market shocks and because they use different private and public support mechanisms. We present results from new high-quality UK data: the Understanding Society COVID-19 Survey. We highlight three important characteristics of data for understanding how households are impacted by economic crises: first, that information is available as a crisis develops; second, an ability to estimate reliably population and subpopulation quantities; third, a link to the economic position of the observed households prior to the crisis.

Two months after the "stay at home" policy was introduced in the UK at the end of March, unemployment had barely increased. However, almost $50 \%$ of the working-age population were not working positive hours, with many protected by the Coronavirus Job Retention Scheme which required them not to work. The data shows that despite being an aggregate shock, and despite the far reaching policies introduced, the impact on individuals was highly heterogeneous. We show that through the first wave of the pandemic, labour market impacts were most negative for individuals from minority ethnic groups and those in the lowest quintile of average pre-COVID-19 income. For many, the impact of the crisis on employment has been mitigated by the Job Retention Scheme, which proved crucial at limiting losses to household earnings in the first wave, though at the cost of delaying sectoral reallocation

\footnotetext{
24 Note this implies over a million new applications.

25 Table 9 in the Online Appendix reports regression results aligning with Table 5.
}

(Barrero et al., 2020). Nonetheless, $45 \%$ of individuals had experienced at least a $10 \%$ decline in household earnings.

We highlight that the welfare costs of these economic shocks depend not just on the size of the direct shocks but also on the mechanisms households have used to mitigate the shocks. We distinguish between self-insurance and external help. Self-insurance through using savings and additional borrowing was highly prevalent. The use of additional borrowing was highest for those who had been hardest hit in the labour market: the lowest income quintiles and minority ethnic groups; as well as for single parents. External support came from transfers from friends and family and from new applications for welfare support. Transfers from friends and family were particularly important for the mostaffected groups. This reliance of some households on borrowing and on private transfers through the first wave of COVID-19 raises the question of whether these households have sustainable mechanisms of mitigation through subsequent waves. This will be particularly important when the Coronavirus Job Protection Scheme ends and those who are notionally employed but not working any hours will move into unemployment or need to adjust.

\section{Appendix A. Supplementary data}

Supplementary data associated with this article can be found, in the online version, at https://doi.org/10.1016/j.jpubeco.2020. 104334.

\section{References}

Adams-Prassl, Abi, Boneva, Teodora, Golin, Marta, Rauh, Christopher, 2020. Inequality in the impact of the coronavirus shock: evidence from real time surveys. J. Public Econ. 189, 104245.

Alstadsæter, Annette, Bratsberg, Eielsen, Gaute, Kopczuk, Wojciech, Markussen, Simen, Raaum, Oddbjorn, Røed, Knut, 2020. The First Weeks of the Coronavirus Crisis: Who Got Hit, When and Why? Evidence from Norway. National Bureau of Economic Research Working Paper 27131.

Barrero, Maria, Jose, Bloom, Nicholas, Davis, Steven J., 2020. Covid-19 is also a reallocation shock.

Béland, Louis-Philippe, Brodeur, Abel, Wright, Taylor, 2020. The short-term economic consequences of Covid-19: exposure to disease, remote work and government response.

Belot, Michèle, Choi, Syngjoo, Jamison, Julian C., Papageorge, Nicholas W, Tripodi, Egon, Van den Broek-Altenburg, Eline, 2020. Unequal Consequences of Covid 19 across Age and Income: Representative Evidence from Six Countries.

Benzeval, Michaela, Bollinger, Christopher R., Burton, Jonathan, Crossley, Thomas F., Lynn, Peter, 2020a. The representativeness of Understanding Society. (202008).

Benzeval, Michaela, Burton, Jon, Crossley, Thomas F., Fisher, Paul, Jäckle, Annette, Low, Hamish, Read, Brendan, 2020b. The Idiosyncratic Impact of an Aggregate Shock The Distributional Consequences of COVID-19. 911.

Blundell, Richard, Joyce, Robert, Keiller, Agnes Norris, Ziliak, James P., 2018. Income inequality and the labour market in Britain and the US. J. Public Econ. 162, 4862.

Bourquin, Pascale, Joyce, Robert, Norris-Keiller, Agnes, 2020. Living standards, poverty and inequality in the UK.

Cortes, Matias, Guido, 2020. Heterogeneous Labor Market Impacts During the Early Stages of the Covid-19 Pandemic. Rimini Centre for Economic Analysis Working Paper series 20-13.

Couch, Kenneth A., Fairlie, Robert W., Huanan, Xu, 2020. Early evidence of the impacts of COVID-19 on minority unemployment. J. Public Econ. 192, 104287.

Couper, Mick P, Kapteyn, Arie, Schonlau, Matthias, Winter, Joachim, 2007. Noncoverage and nonresponse in an Internet survey. Soc. Sci. Res. 36 (1), 131-148.

Fisher, Paul, Fumagalli, Laura, Buck, Nick, Avram, Silvia, 2019. Understanding Society and its income data. (2019-08).

Fitzgerald, John, Gottschalk, Peter, Moffitt, Robert, 1998. An analysis of sample attrition in panel data: the Michigan panel study of income dynamics. J. Hum. Resour. 33 (2), 251-299.

Institute for Social and Economic Research, 2020a. Understanding Society COVID-19 Study, 2020. [data collection]. 1st Edition. UK Data Service. SN: 8644, DOI: 10.5255/UKDA-SN-8644-1.

Institute for Social and Economic Research. 2020b. Understanding Society COVID19 User Guide. Version 1.0. University of Essex, Colchester.

Lynn, Peter, Olena, Kaminska, 2010. Weighting strategy for Understanding Society. (2010-05). 
Micklewright, John, Schnepf, Sylke V., 2010. How reliable are income data collected with a single question?. J. Roy. Stat. Soc.: Ser. A (Stat. Soc.) 173 (2), 409-429.

Moffit, Robert, Fitzgerald, John, Gottschalk, Peter, 1999. Sample attrition in panel data: the role of selection on observables. Annales d'Economie et de Statistique, 129-152.

Montenovo, Laura, Jiang, Xuan, Rojas, Felipe Lozano, Schmutte, Ian M., Simon, Kosali I., Weinberg, Bruce A., Wing, Coady, 2020. Determinants of Disparities in Covid-19 Job Losses. National Bureau of Economic Research Working Paper 27132.

Nicoletti, Cheti, Peracchi, Franco, 2005. Survey response and survey characteristics: microlevel evidence from the European Community Household Panel. J. Roy. Stat. Soc.: Ser. A (Stat. Soc.) 168 (4), 763-781.

Schonlau, Matthias, Van Soest, Arthur, Kapteyn, Arie, Couper, Mick, 2009. Selection bias in web surveys and the use of propensity scores. Sociol. Meth. Res. 37 (3), 291-318.
Schröder, Carsten, Entringer, Theresa Margareta, Goebel, Jan, Grabka, Markus M. Graeber, Daniel, Kroh, Martin, Kröger, Hannes, Kühne, Simon, Liebig, Stefan, Schupp, Jürgen, et al., 2020. Covid-19 is not affecting all working people equally. University of Essex Institute for Social and Economic Research, NatCen Social Research, and Kantar Public, n.d. Understanding Society: Waves 1-9, 20092018 and Harmonised BHPS: Waves 1-18, 1991-2009. [data collection]. 12th Edition.

Valliant, Richard, Dever, Jill, 2018. Survey Weights: A Step-by-step Guide to Calculation. Stata Press College Station, TX.

von Gaudecker, Hans-Martin, Holler, Radost, Janys, Lena, Siflinger, Bettina, Zimpelmann, Christian, 2020. Labour Supply in the Early Stages of the COVID19 Pandemic: Empirical Evidence on Hours, Home Office, and Expectations. IZA Institute of Labor Economics Working Paper 13158.

Wooldridge, Jeffrey M., 2002. Inverse probability weighted M-estimators for sample selection, attrition, and stratification. Portuguese Econ. J. 1 (2), 117-139. 